\title{
An approach to simulate the climate-driven streamflow in the data-scarce mountain basins of Northwest China
}

\author{
Chong Wang ${ }^{1,2,3}$, Jianhua $\mathrm{Xu}^{2,3, *}$ (i), Yaning Chen ${ }^{4}$ and Weihong $\mathrm{Li}^{4}$ \\ ${ }^{1}$ School of Social Sciences, Shanghai University of Engineering Science, Shanghai 201 620, \\ People's Republic of China. \\ ${ }^{2}$ Key Laboratory of Geographic Information Science (Ministry of Education), School of Geographic Sciences, \\ East China Normal University, Shanghai 200 241, People's Republic of China. \\ ${ }^{3}$ Research Center for East-West Cooperation in China, East China Normal University, Shanghai 200241 , \\ People's Republic of China. \\ ${ }^{4}$ State Key Laboratory of Desert and Oasis Ecology, Xinjiang Institute of Ecology and Geography, Chinese \\ Academy of Sciences, Urumqi 830 011, People's Republic of China. \\ *Corresponding author. e-mail: jhxu@geo.ecnu.edu.cn
}

MS received 14 March 2018; revised 27 August 2018; accepted 27 September 2018; published online 2 April 2019

With global warming, the inland river basin in the arid region of Northwest China is facing a serious water supply situation. The headwater basin of the inland river is located in the high-altitude mountainous region, and there are few meteorological observation sites, so it is difficult to apply distributed hydrological models and other models based on the physical mechanism of runoff generation to evaluate climate change and its impact on streamflow. To simulate the climate-driven streamflow in datascarce mountain basins of Northwest China, we developed an integrated approach by using downscaled reanalysis data, Mann-Kendall test, ensemble empirical mode decomposition and backpropagation artificial neural networks together with the weights connection method. We validated the approach in the Kaidu River basin located in the Tianshan mountains. The results showed that the streamflow increased $12.9 \%$ by $2.5 \times 10^{8} \mathrm{~m}^{3}$ per decade with the warm and wet climate, while the average annual temperature increased $5.2 \%$ at a rate of $0.3^{\circ} \mathrm{C}$ per decade and the precipitation increased $37.3 \%$ at a rate of $16.4 \mathrm{~mm}$ per decade during the period from 1980 to 2015. The impact of temperature variability on streamflow was $44.21 \pm 2.08 \%$ and the impact of precipitation variability on streamflow was $55.79 \pm$ $2.08 \%$.

Keywords. Climate change; impact; streamflow; data-scarce mountainous basins; Northwest China.

\section{Introduction}

Climate change affects hydrological processes (Yao et al. 2018). The trend analysis of climate variables reveals the process of climate change. Temperature and precipitation are climate variables which are mainly affected by global warming. So the key point for hydrological forecasting is to understand the hydrological processes affected by temperature and precipitation. Research in different countries and regions has shown that the hydroclimatic processes are complex systems and have nonlinear features (Sivakumar 2010; Xu et al. 2011).

In recent years, there has been plenty of research in the field of hydroclimatic processes including regression method, fitting by spline or empirical 
function, Mann-Kendall trend test, Pettitt's test for single change-point detection (Li et al. 2012), singular spectrum analysis (Wang et al. 2013), wavelet decomposition and reconstruction method, empirical orthogonal functions and artificial neural networks (Xu et al. 2014).

Empirical statistics model is an effective way to simulate hydroclimatic processes. Based on the analysis of runoff and precipitation at various stations and various soil and water conservation measures, Mu et al. (2004) established a statistical hydrological model of precipitation soil and water conservation runoff in basins using multiple regression methods. Chen et al. (2003) established six empirical models for streamflow simulation in the inland mountainous regions of Northwest China and found that there was a high degree of correlation between climate factors and streamflow. Especially, in mountainous areas, where there were more glaciers and more snow, the temperature was a very important factor.

The soil and water assessment tool (SWAT; Arnold et al. 1998; Arnold and Fohrer 2005) is a distributed model widely applied in runoff simulation and hydrologic process analyses (Pereira et al. 2016; Ghane et al. 2017). SWAT is developed based on the simulator for water resources in rural basins model (USDA Agricultural Research Service contributes to the development of SWAT with modelling experience that spans nearly 30 yr (Yang and Musiake 2003; Lévesque and Anctil 2008; Shope et al. 2014). The construction of distributed hydrological model requires sufficient parameters and drive data sets (Yang et al. 2015). Especially, in the high mountains, such as the Tianshan mountains, Qilian mountains and the Kunlun mountains, in the vast area of Northwest China, the rare observation sites result in the lack of meteorological and hydrological data with high spatial resolution. All the reasons above make it difficult to simulate the climate-driven streamflow and estimate the impact of climate change on streamflow in data-scarce mountain basins. Therefore, it is necessary to develop an approach further for modelling the hydroclimatic process in the data-scarce mountain basins of Northwest China.

Along with global warming, the water supply situation in the inland mountainous basin has become more and more serious. Since the inland mountainous basin is located in a high-altitude region, there are few meteorological observation sites. It is difficult to create distributed hydrological models to assess climate change and its impact on streamflow. Therefore, it is necessary to develop a comprehensive model based on downscaled earth data products to simulate the hydroclimatic process and quantitatively assess the impact of climate change on streamflow.

For the purpose of simulating the climate-driven streamflow and for assessing the impact of climate change to streamflow in data-scarce mountain basins of Northwest China, this work developed an integrated approach by using downscaled reanalysis data, Mann-Kendall test, ensemble empirical mode decomposition (EEMD), backpropagation artificial neural networks (BPANN) together with weights connection method. We validated the approach by selecting the Kaidu River basin in the Tianshan mountains of Northwest China. The combined approach can effectively simulate the change of climate and streamflow in the basin lacking observational data, quantitatively identify the impacts of changes in temperature and precipitation on the streamflow in typical valleys on the southern slope of the Tianshan mountains and provide a framework for hydrological simulation and water resources management in inland mountainous regions.

\section{Materials and methods}

\subsection{Description of the study area}

We selected the Kaidu River basin as the study area because it is a typical data-scarce mountain basin, which is located on the southern slope of the middle Tianshan mountains and the northern edge of the Tarim basin. There is one meteorological and one hydrological station in the study area (figure 1) $\left(82^{\circ} 58^{\prime}-86^{\circ} 55^{\prime} \mathrm{E} ; 41^{\circ} 47^{\prime}-43^{\circ} 21^{\prime} \mathrm{N}\right)$. The river originated in the Jacsta Valley and the Hargat Valley in the Sarming mountain and ended at the Bosten Lake. The basin area of the Kaidu River above Dashankou is $18,827 \mathrm{~km}^{2}$, with an average elevation of $3100 \mathrm{~m}$. The average annual temperature in the basin is $4.6^{\circ} \mathrm{C}$, the extreme maximum temperature is $25.27^{\circ} \mathrm{C}$ and the extreme minimum temperature is $-48.1^{\circ} \mathrm{C}$. The yearly snow-cover days are 139.3 days, and the largest average yearly snow depth is $12 \mathrm{~cm}$.

\subsection{Data sources}

The elevation data for downscaled reanalysis data was extracted from the Shuttle Radar Topography Mission (SRTM) $90 \mathrm{~m}$ digital elevation model data 


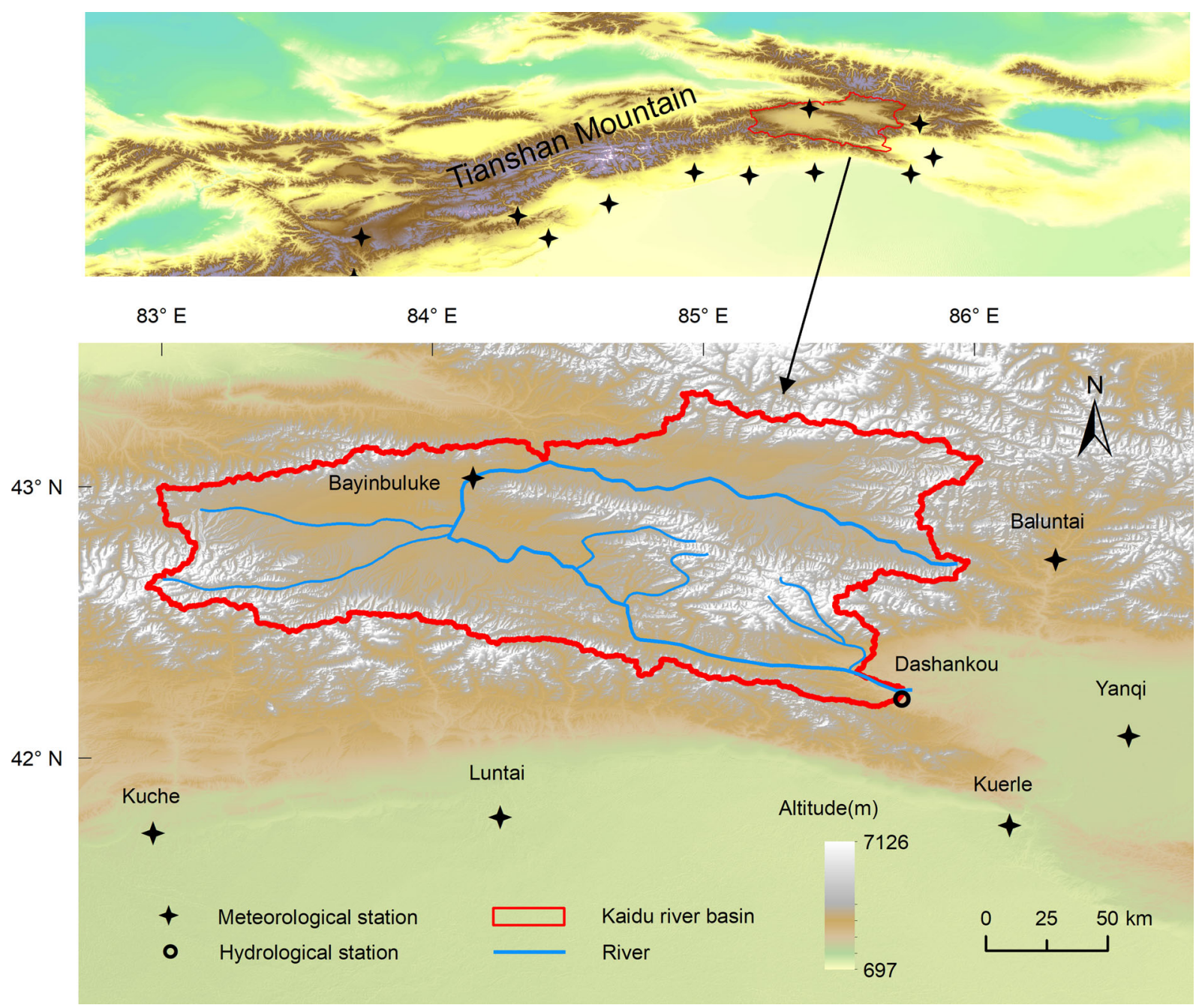

Figure 1. Locations of Kaidu River basin, meteorological stations and hydrological stations.

V4.1. International Center for Tropical Agriculture (Reuter et al. 2007) preprocessed the SRTM DEM data, and the data can be downloaded from United States Geological Survey/National Aeronautics and Space Administration (http://srtm.csi. cgiar.org). The grid cell size of SRTM is $90 \mathrm{~m}$.

To reveal the climate characteristics in datascarce mountain basins, we chose the reanalysis data for downscaling. Based on the accuracy test of reanalysed data products (MERRA-2 instM_2d_lfo_ $\mathrm{Nx}$ V5.12.4, ERA-Interim $2 \mathrm{~m}$ temperature data and China's surface air temperature $0.5^{\circ} \times 0.5^{\circ}$ grid dataset), we chose the MERRA-2 instM_2d_lfo_Nx V5.12.4 data for downscaling. The MERRA-2 data can be downloaded from the web of Global Modeling and Assimilation Office (http://goldsmr4. gesdisc.eosdis.nasa.gov). The spatial resolution of the monthly temperature data is $0.5^{\circ} \times 0.625^{\circ}$. Since the most reanalysed data starts in 1980, the date range of this research is all from January 1980 to December 2015.
We chose the China precipitation grid data V2.0 provided by National Meteorological Information Center (NMIC) (http://data.cma.cn) for downscaling. The grid size of the monthly precipitation is $0.5^{\circ}$ and the date range is from January 1980 to December 2015.

We used the measured meteorological data provided by NMIC (http://data.cma.cn) to test the downscaling model effect. The meteorological station for verification is Bayinbuluke, which is the only national base weather station in the Kaidu River basin. The time resolution is monthly, and the date range is from January 1980 to December 2015.

The long-term hydrological station monitoring streamflow data offered by Xinjiang Tarim River Basin Management Bureau was used to verify the stream simulation effect. The monitoring station is Dashankou at the outlet of the Kaidu River basin. The monthly data is in ASCII format and the period is from 1980 to 2015 . 


\subsection{Methods}

We used an integrated approach for simulating the climate-driven streamflow in the data-scarce mountain basins (figure 2). The integrated approach contains three processes. The reanalysis data was downscaled and tested at first. Then the Mann-Kendall trend test and EEMD methods were used to detect the trends and decompose the monthly temperature, precipitation and streamflow data into different scales. At last, a BPANN was trained with the downscaled regional climate mean values. The weights of each layer in the BPANN were connected and the impact of climate variation on streamflow was evaluated.

\subsubsection{Downscaling the reanalysis data}

With the development of technology, the atmospheric reanalysis data and downscaling technique provide the complete fields in space and time of the hydrological variables (Huth et al. 2015). Downscaling the reanalysis data could be applied in the research of simulating the impact of climate change on streamflow (Emanuel et al. 2010; Strzepek et al. 2013; Koster et al. 2017).

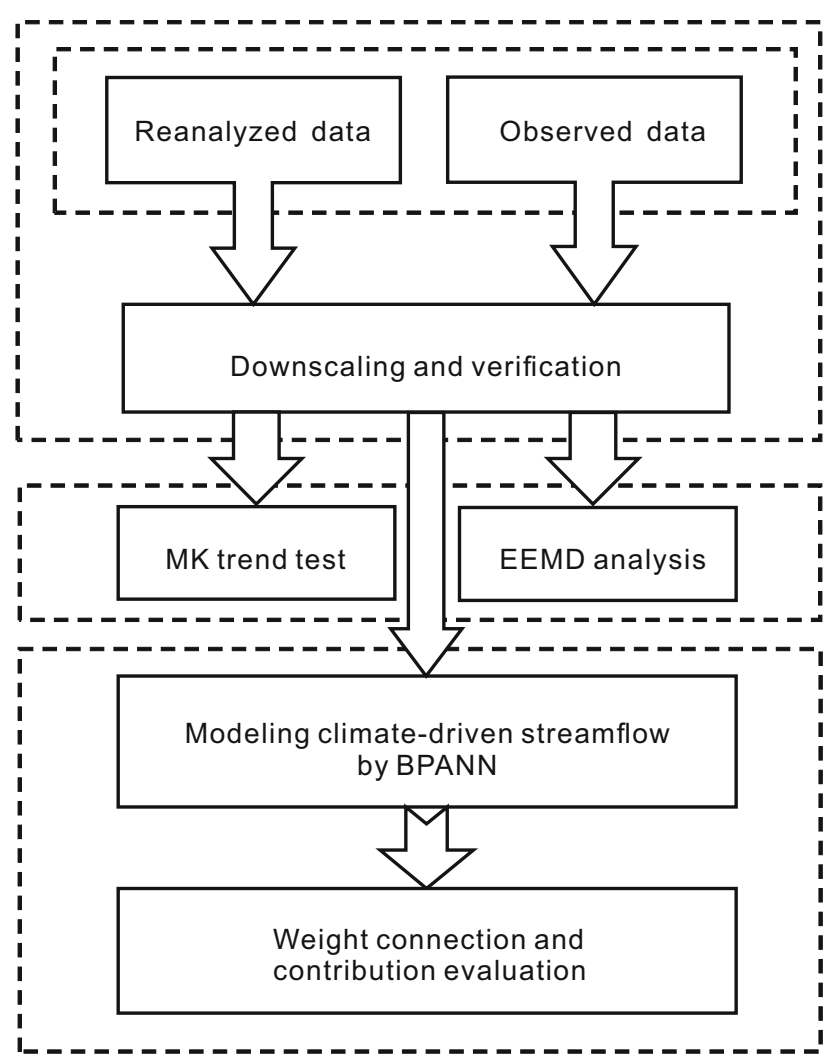

Figure 2. Framework of an integrated approach to downscale reanalysis data, detect the trends and model the hydroclimatic process.
The Kaidu River basin has just one national long-term observation meteorological station in Bayanbulak, so the climate data is scarce and could not represent the overall climate variation in the complex mountain basin. The variability of temperature and precipitation is related to altitude. With the altitude data, we can downscale the reanalysis data of temperature and precipitation to reveal the regional climate characteristics (Xu et al. 2013; Georgakakos et al. 2014). An improved downscaling method, which can dynamically adjust the parameter based on terrain feature (Wang et al. 2018), was applied to downscale the reanalysis data. The downscaling method includes temperature lapse rates, simulation of precipitation gradients, reanalysis of climate data downscaling and basin's monthly temperature and precipitation calculation.

We simulated the temperature lapse rates and precipitation gradients with meteorological stations along with the south slope of Tianshan mountains (Baluntai, Yanqi, Korla, Luntai, Bayanbulak, Kuqa, Baicheng, Aksu, Kalpin, Akqi, Torugart, Kashgar and Wuqia) from 1980 to 2015 at first. The average monthly temperature $t_{i}$ and average monthly precipitation $p_{i}$ were calculated at first to reduce the impact of parameter error on downscaling.

Existing studies in Northwest China have shown that (Fu et al. 2013; Wang et al. 2018) the altitude $h$ and temperature $t$ have a linear relationship, while the altitude $h$ and precipitation $p$ have a quadratic polynomial relationship. So, a linear equation $t=m h+n$ and a quadratic polynomial equation $p=\mathrm{a} h^{2}+b h+c$ were fitted to downscale the reanalysed temperature and precipitation data. The parameters (i.e., $m, n, a, b, c$ ) were estimated with meteorological observations. The fitting effect was tested with $R^{2}$ (coefficient of determination) and $F$ test. $R^{2}$ was calculated with the following equation:

$$
R^{2}=1-\frac{\sum_{i=1}^{k}\left(y_{i}-\hat{y}_{l}\right)^{2}}{\sum_{i=1}^{k}\left(y_{i}-\bar{y}_{l}\right)^{2}},
$$

where $y_{i}, \hat{y}_{l}$ and $\bar{y}_{l}$ are the observed, simulated and average values of meteorological time series, respectively, and $k$ is the length of the meteorological observation series.

Then, we calculated the temperature lapse rate $\mathrm{d} t / \mathrm{d} h$ and the precipitation gradient $\mathrm{d} t / \mathrm{d} h$ by 
calculating the derivative of fitting functions:

$$
\begin{aligned}
& \frac{\mathrm{d} t}{\mathrm{~d} h}=m, \\
& \frac{\mathrm{d} p}{\mathrm{~d} h}=2 a h+b .
\end{aligned}
$$

With equations (4 and 5) and changing values of altitude between reanalysis data and SRTM data, the monthly reanalysis climate data was downscaled. Firstly, based on the altitude of SRTM $h_{\mathrm{s}}$ and bilinear interpolation resampling method, the elevation of the reanalysis data $h_{\mathrm{r}}$ was calculated. To facilitate the matrix operation among different grid sizes, the reanalysis temperature data $t_{\mathrm{r}}$, reanalysis precipitation data $p_{\mathrm{r}}$ and $h_{\mathrm{r}}$ were resampled to the grid size same as $h_{\mathrm{s}}$ by bilinear interpolation. Then the downscaled monthly temperature $t_{\mathrm{d}}$ and monthly precipitation $p_{\mathrm{d}}$ with the spatial resolution of $90 \mathrm{~m}$ at the elevation $h_{\mathrm{s}}$ were obtained by equations ( 6 and 7 ):

$$
\begin{aligned}
& t_{\mathrm{d}}=t_{\mathrm{r}}+\left(h_{\mathrm{s}}-h_{\mathrm{r}}\right) \cdot\left(\frac{\mathrm{d} t}{\mathrm{~d} h_{\mathrm{s}}}+\frac{\mathrm{d} t}{\mathrm{~d} h_{\mathrm{r}}}\right) / 2, \\
& p_{\mathrm{d}}=p_{\mathrm{r}}+\left(h_{\mathrm{s}}-h_{\mathrm{r}}\right) \cdot\left(\frac{\mathrm{d} p}{\mathrm{~d} h_{\mathrm{s}}}+\frac{\mathrm{d} p}{\mathrm{~d} h_{\mathrm{r}}}\right) / 2,
\end{aligned}
$$

where $\left(h_{\mathrm{S}}-h_{\mathrm{r}}\right)$ is the change value of elevation, $\left(\left(\mathrm{d} t / \mathrm{d} h_{\mathrm{s}}\right)+\left(\mathrm{d} t / \mathrm{d} h_{\mathrm{r}}\right)\right) / 2$ is the average temperature lapse rates between elevation $h_{\mathrm{s}}$ and $h_{\mathrm{r}}$, $\left(\left(\mathrm{d} p / \mathrm{d} h_{\mathrm{s}}\right)+\left(\mathrm{d} p / \mathrm{d} h_{\mathrm{r}}\right)\right) / 2$ is the average precipitation gradients between elevation $h_{\mathrm{s}}$ and $h_{\mathrm{r}}$.

With equations (4 and 5), the downscaling equations are as follows:

$$
\begin{aligned}
& t_{\mathrm{d}}=t_{\mathrm{r}}+\left(h_{\mathrm{s}}-h_{\mathrm{r}}\right) \cdot m, \\
& p_{\mathrm{d}}=p_{\mathrm{r}}+\left(h_{\mathrm{s}}-h_{\mathrm{r}}\right) \cdot\left[a\left(h_{\mathrm{s}}+h_{\mathrm{r}}\right)+b\right] .
\end{aligned}
$$

The downscaled time series at the meteorological station Bayanbulak were extracted by the nearestneighbour method which means selecting the closest cell value from the meteorological station as the extracted value of this point. We measured the performance of the downscaling model by calculating Slope, NSE (Nash-Sutcliffe efficiency coefficient), MAE (mean absolute difference) and RMSE (rootmean-square error) between downscaled time series and observation series.

The basin temperature and precipitation for each month were calculated by the arithmetic average method. Then we can get the average basin temperature and total basin precipitation each year. Mann-Kendall trend test, Pettitt's test, and Sen's slope were used to detect the trend and change point of the basin annual average temperature and annual total precipitation. Seasonal Mann-Kendall test, seasonal Mann-Kendall test with correlations and seasonal Sen's slope were used to detect the trend of basin's monthly temperature and precipitation.

\subsubsection{Non-parametric trend test}

The Mann-Kendall trend test, the seasonal MannKendall test, seasonal Mann-Kendall test with correlations, the Sen's slope, the seasonal Sen's slope and Pettitt's test were used to detect linear trends in climate or hydrologic time series (Khaliq et al. 2009; Sonali and Kumar 2013). The use of multiple test methods can mutually verify the reliability of the test results.

The null hypothesis $\mathrm{H}_{0}$ of the Mann-Kendall trend test (Mann 1945; Kendall 1948) assumes that the data comes from independent random variables and has the same distribution. The alternative hypothesis $\mathrm{H}_{1}$ is that the data presents a monotonous trend. For the time series $X_{t}=$ $\left(x_{1}, x_{2}, K, x_{n}\right)$, the statistic $S$ of the Mann-Kendall test is calculated according to the following formula:

$$
S=\sum_{i=1}^{n-1} \sum_{k=i+1}^{n} \operatorname{sgn}\left(X_{k}-X_{i}\right)
$$

where $n$ represents the length of the sample data, $X_{i}$ represents the $i$ th data of the time series and sgn represents the symbolic function, which is defined as

$$
\operatorname{sgn}(\theta)= \begin{cases}1, & \theta>0, \\ 0, & \theta=0, \\ -1, & \theta<0 .\end{cases}
$$

For a set whose sample size is greater than or equal to 8 , the statistic $S$ is close to a normal distribution, its mean is 0 and the variance is

$$
\begin{aligned}
& \operatorname{Var}(s) \\
& =\frac{n(n-1)(2 n+5)-\sum_{i=1}^{n} t_{i}(i-1)(2 i+5)}{18},
\end{aligned}
$$

where $t_{i}$ is the number of data in the $i$ th group. 
The standardised statistic $Z_{\mathrm{c}}$ is calculated as follows:

$$
Z_{c}= \begin{cases}\frac{S-1}{\sqrt{\operatorname{Var}(s)}}, & S>0, \\ 0, & S=0, \\ \frac{S+1}{\sqrt{\operatorname{Var}(s)}}, & S<0,\end{cases}
$$

where $Z_{c}$ is a trend statistic. If $Z_{c}$ is positive, it means that the tested series shows an increasing trend. If $Z_{c}$ is negative, it means a decreasing trend. Zero hypothesis $\mathrm{H}_{0}$ is that there is no significant change in the time series. If the absolute value of $Z_{c}$ is greater than the statistical value corresponding to the $95 \%$ confidence level of 1.96 , the null hypothesis is rejected, indicating that the sequence change trend is significant.

For the $g$ th season, the Mann-Kendall test statistic $S_{g}$ is calculated as follows:

$$
\begin{gathered}
S_{g}=\sum_{i=1}^{n-1} \sum_{j=i+1}^{n} \operatorname{sgn}\left(X_{j g}-X_{i g}\right), \\
g=1,2, \ldots, m .
\end{gathered}
$$

According to the study of Hirsch et al. (1982), the statistics of the seasonal Mann-Kendall test for all seasons $\hat{S}$ is calculated by

$$
\hat{S}=\sum_{g=1}^{m} S_{g}
$$

For more information on the seasonal MannKendall test can be found in some related literature (Hirsch et al. 1982; Hipel and Mcleod 1994). If the elements of the time series are related, the correlated seasonal Mann-Kendall test can be applied (Hipel and Mcleod 1994).

The Sen's slope test calculates the slope (i.e., the linear rate of change) using the Sen method. First, a set of linear slopes is calculated as follows:

$$
d_{k}=\frac{X_{j}-X_{i}}{j-i} .
$$

For $1 \leq i<j \leq n, d$ is the slope, $X$ is the variable, $n$ is the length of the data, and $i$ and $j$ are subscripts.

Sen's slope is calculated by calculating the median of all slopes:

$$
b=\text { Median } d_{k} .
$$

A study by Hirsch et al. (1982) shows that the seasonal Sen's slope is calculated by

$$
d_{i j k}=\frac{X_{i j}-X_{i k}}{j-k}
$$

For any number of pairs $X_{i j}, X_{i k}, i=1,2, \ldots, m$, where $1 \leq k<j \leq n_{i}, n_{i}$ is the number of values in the $i$ th season. The estimate value of seasonal Sen's slope is the median $d_{i j k}$.

Pettitt (1979) proposed Pettitt's test, a mutation point detection method, which has been widely used for the detection of mutations in meteorological and hydrological time series. The null hypothesis $\mathrm{H}_{0}$ of Pettitt's test is that the $T$ variable follows the distribution of one or more of the same parameters. The alternative hypothesis is that there is a point of mutation. Non-parametric test statistics are defined as

$$
K_{T}=\max \left|U_{t, T}\right|
$$

where

$$
U_{t, T}=\sum_{i=1}^{t} \sum_{j=t+1}^{T} \operatorname{sgn}\left(X_{i}-X_{j}\right) .
$$

The mutation point in the time series is at $K_{T}$ and the significance level is calculated by the following formula:

$$
p \cong 2 \exp \left(\frac{-6 K_{T}^{2}}{T^{3}+T^{2}}\right)
$$

\subsubsection{Ensemble empirical mode decomposition}

EEMD is a new signal detection method which overcomes the scale-mixing problem and is an improvement of the EMD method (Huang et al. 1998). We use the EEMD method to decompose temperature, precipitation and streamflow, calculate the intrinsic mode function (IMF) components and reconstruct them to obtain the characteristics on different time scales. We can analyse the relationship among the temperature, precipitation and streamflow on different time scales. The EEMD method decomposes a time series $x(t)$ into adaptively obtained, amplitude-frequency modulated oscillatory components $C_{i}(i=1,2, \ldots, n)$ (Wu and Huang 2009) and extracts a residual $R_{n}$, a curve either monotonic or containing only one extremum from which no additional oscillatory 
components:

$$
x(t)=\sum_{i=1}^{n} C_{i}(t)+R_{n}(t) .
$$

As demonstrated in the previous studies (Qian et al. 2011; Qian and Zhou 2014; Bai et al. 2015), the extracted trend $\left(R_{n}\right)$ follows no a priori shape and varies with time after the intrinsic variability of multi-decadal and shorter timescales is removed. Unlike traditional methods, EEMD does not need to specify a priori basis function. It adopts natural waveforms (Feng et al. 2014) to guarantee the physical interpretation within specified time intervals and does not change with the addition of new data (Ji et al. 2014).

The energy distribution was examined to determine the scales of IMF components. The energy density of the $i$ th IMF components $\left(E_{i}\right)$ was defined as equation (11):

$$
E_{i}=\frac{1}{N} \sum_{j=1}^{N}\left|I_{i}(j)\right|^{2},
$$

where $N$ is the length of the IMF component and $I_{i}(j)$ denotes the $i$ th IMF component. The white noise sequence is tested by the Monte Carlo method (Wu and Huang 2004); then, a simple equation that relates the energy density $\left(\bar{E}_{l}\right)$ and the averaged period $\left(\bar{T}_{l}\right)$ is obtained:

$$
\lg \bar{E}_{l}+\lg \left(\bar{T}_{l}\right)_{a}=0 .
$$

With $\lg \left(\bar{T}_{l}\right)_{a}$ and $\lg \bar{E}_{l}$ as $X$-axis and $Y$-axis, the relationship between the averaged period and the energy density was linear and the slope of the fitting line was -1 . In theory, the IMF component of the white noise series should distribute on the line, while deviation exists in actual application. So the confidence interval for the energy spectrum distribution of white noise was calculated as follows:

$$
\lg \bar{E}_{l}=-\lg \left(\bar{T}_{l}\right)_{a} \pm a \sqrt{2 / N} \mathrm{e}^{\lg \left[\left(\bar{T}_{l}\right)_{a / 2}\right]},
$$

where $a$ is the significance level.

The standard deviation of white noise is used to eliminate the noise in the original signal. It is determined by the noise interference in the original signal. The standard deviation of Gaussian white noise is generally set to $0.01-0.4$ which is determined based on the signal; the ensemble number is used to set the number of times the noise is added, which usually takes 50 or 100 . In this research, with downscaled meteorological data and hydrological series in a mountain basin, the climate and streamflow variability in different scales were abstracted with the EEMD method. In the EEMD method, the ensemble number was set as 100 and added white noise was set to 0.2 times of standard deviation (Feng et al. 2012). Also, the decomposed IMFs have been tested for the significance. To reduce the impact of edge effects in EEMD decomposition, mirror-symmetric extension (Huang and Shen 2005) was adopted to pre-process the input time series.

\subsubsection{Backpropagation artificial neural network}

BPANN was constructed to simulate the nonlinear relationship of streamflow driven by climate change with the downscaled temperature and precipitation series. BPANN is a useful tool to simulate the complex climate and hydrological relationships (Xu et al. 2013, 2016; Loukas and Vasiliades 2014). In this research, we constructed a network that contained two nodes in the input layer, $5 \times 5$ nodes in the hidden layers and one node in the output layer (figure 3 ). In the network, $t_{m}$ and $p_{m}$ were the input time series, $s_{m}$ was the target time series to train the network, $w_{i j}$ was the weight from the $i$ th node in the input layer to the $j$ th node in the hidden layer, $w_{j k}$ was the weight from the $j$ th node in the hidden layer 1 to the $k$ th node in the hidden layer 2 , and $w_{k l}$ was the weight from the $k$ th node in the hidden layer to the $l$ th node in the output layer.

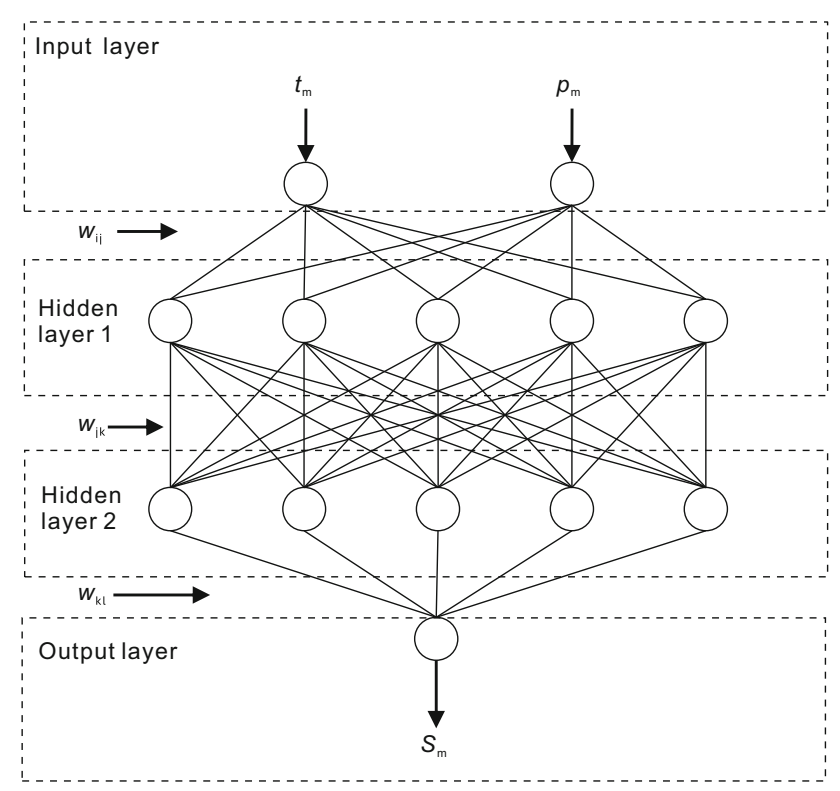

Figure 3. Input layer, hidden layer, an output layer, nodes and weights of the BPANN. 
The nodes in the same layer did not connect to each other and just connected to the node in the next layer. In training, the information was transmitted forward and the error was propagated back. In total, $70 \%$ of the input and target series was selected as the training group, $15 \%$ were selected as the calibration group, and $15 \%$ were selected as the validation group. The information from one layer to another was transmitted by an activation function. This study chose the sigmoid function as the activation function. If the simulated series does not equal to the observed sequence, the error would be backpropagated. The connection weights were optimised by gradient descent algorithm with the backpropagated error from the output nodes to the input node. The LevenbergMarquardt algorithm was used to accelerate the convergence. The neural network with the minimum square error was selected as the optimal fitting result of one BPANN fitting after 1000 pieces of training.

To reduce the impact of the initial randomised parameters in training, we trained the BPANN many times. Then the mean of the simulated streamflow was calculated as the final output. In this research, the mean value of the outputs was relatively stable after 10 fittings after testing. The Slope, $R^{2}$, MAE and RMSE were calculated to test the performance of BPANN.

\subsubsection{Impact of climate change on streamflow}

BPANN could fit the non-linear relationship with high precision, while its ability to explain the relationship among variables remains to be explored further. Therefore, an improved weight connection method was used based on previous research studies (Olden and Jackson 2002; Olden et al. 2004; Fischer 2015; Wang et al. 2018) to evaluate the impact of climate change on streamflow quantitatively. We obtain the total weight by adding the absolute value of the positive weights and the negative weights avoiding the offsetting of the weights.

Firstly, we calculated the cumulative weight from the input layer to the output layer as follows:

$$
w_{\mathrm{io}}=\left[\begin{array}{c}
w_{\mathrm{ts}} \\
w_{\mathrm{ps}}
\end{array}\right]=w_{\mathrm{ih}_{1}} \times w_{\mathrm{h}_{1} \mathrm{~h}_{2}} \times w_{\mathrm{h}_{2}} \mathrm{O},
$$

where $w_{\text {io }}$ is the cumulative weight matrix from the input layer to the output layer, $w_{\mathrm{ts}}$ is the cumulative weight matrix from temperature to streamflow, $w_{\mathrm{ps}}$ is the cumulative weight matrix from precipitation to streamflow, $w_{\mathrm{ih}_{1}}$ is the weight matrix $(2 \times 5)$ between the input layer and the hidden layer $1, w_{\mathrm{h}_{1} \mathrm{~h}_{2}}$ is the weight matrix $(5 \times 5)$ between the hidden layer 1 and the hidden layer $2, w_{\mathrm{h}_{2}}$ o is the weight matrix $(5 \times 1)$ between the hidden layer 2 and the output layer,

The impact could be calculated as equations (15 and 16):

$$
\begin{aligned}
C_{\mathrm{ts}} & =\frac{\left|w_{\mathrm{ts}}\right|}{\left|w_{\mathrm{ts}}\right|+\left|w_{\mathrm{ps}}\right|} \times 100 \%, \\
C_{\mathrm{ps}} & =\frac{\left|w_{\mathrm{ps}}\right|}{\left|w_{\mathrm{ts}}\right|+\left|w_{\mathrm{ps}}\right|} \times 100 \%,
\end{aligned}
$$

where $C_{\mathrm{ts}}$ is the impact of temperature variability on streamflow and $C_{\mathrm{ps}}$ is the impact of precipitation variability on streamflow.

\section{Results and discussion}

\subsection{Downscaling verification}

To provide parameters for the downscaling method, we first fitted functions between the meteorological factors and altitude (table 1). Based on limited observed data, the temperature and altitude have a strong linear relationship $\left(R^{2}=0.77\right)$ which is significant $(F=678.7, a=0.001)$. It can be seen from the slope of a linear function that when the altitude increases $1000 \mathrm{~m}$, the temperature drops $6.3^{\circ} \mathrm{C}$. The precipitation and altitude have a strong quadratic polynomial relationship $\left(R^{2}=\right.$ $0.799)$ which is significant $(F=179.4, a=0.001)$. With increasing of the altitude, the precipitation increases first and then decreases at about $3000 \mathrm{~m}$ which is consistent with the study in the Tianshan

\begin{tabular}{|c|c|c|c|c|c|c|}
\hline \multirow[b]{2}{*}{$N$} & \multicolumn{3}{|c|}{ Temperature } & \multicolumn{3}{|l|}{ Precipitation } \\
\hline & Function & $R^{2}$ & $F$ & Function & $R^{2}$ & $F$ \\
\hline 468 & $t=-0.0063 \times h+17.847$ & 0.77 & $678.7^{*}$ & $p=-5 \times 10^{-5} \times h^{2}+0.3089 \times h-189.09$ & 0.66 & $179.4^{*}$ \\
\hline
\end{tabular}
mountains (Chen et al. 2013).

Table 1. Functional relationship between the temperature and precipitation changes with altitude.

Note: $F$ test indicates the significance of the functions. ${ }^{*}$ Indicates the significance of $a=0.001$. 
With the verified parameters, we downscaled the reanalysed temperature and precipitation data and then reconstruct the mountainous high-resolution climate distribution data. The downscaled temperature and precipitation are consistent with the observed values in the Bayanbulak meteorological station (figure 4). The slope of trend line between the observed and downscaled scatter plots is close to 1, which represents the high fitting accuracy of downscaled data to the observed data. The $R^{2}$ of the trend line is also close to 1 . Above all, the downscaling method can reconstruct the climate change in the data-scarce mountain basins.

\subsection{Climate and streamflow variability and multi-scale features}

The descriptive statistics and trend test of average annual temperature, annual precipitation and

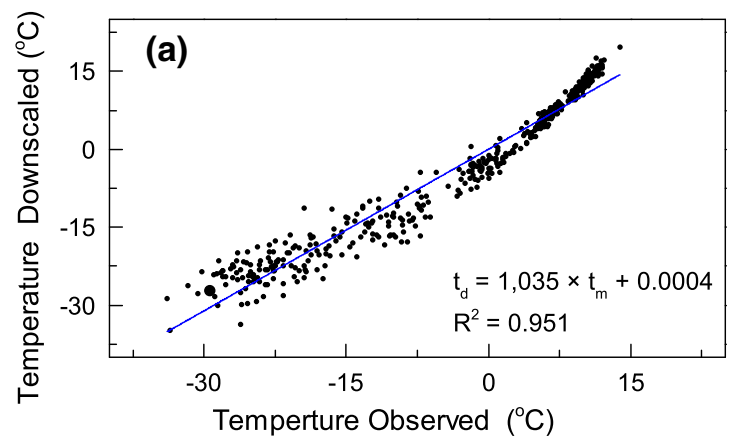

annual streamflow are shown in table 2. The average annual temperature from 1980 to 2015 shows an increasing trend $(Z=1.87)$ at a rate of $0.3^{\circ} \mathrm{C}$ per decade by using the Mann-Kendall trend test. The annual precipitation shows a significant increasing trend $(Z=1.98, a=0.05)$ at the rate of $16.4 \mathrm{~mm}$ per decade. The annual streamflow increases significantly $(Z=2.71, a=0.01)$ at a rate of $2.5 \times 10^{8} \mathrm{~m}^{3}$ per decade with the rising temperature and precipitation. The Sen's slope is consistent with the linear slope and also shows the increasing trend of temperature, precipitation and streamflow. The Pettitt's test detects mutation year of temperature, precipitation and streamflow in $1997(a=0.02), 1994(a=0.05)$ and 2000 $(a=0.001)$.

The seasonal Mann-Kendall test (table 3) shows that the monthly temperature, precipitation and

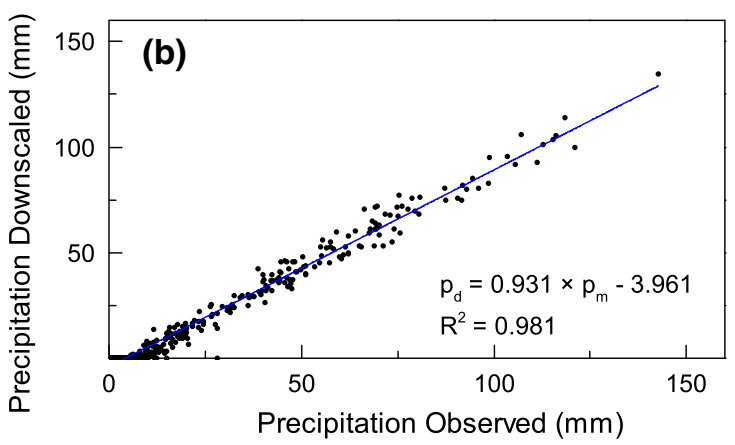

Figure 4. Scatter plot and trend line of the downscaled and observed monthly temperature and precipitation series in the verification station.

Table 2. Descriptive statistics and trend test of the annual temperature, precipitation and streamflow from 1980 to 2015.

\begin{tabular}{|c|c|c|c|c|c|c|c|c|c|}
\hline \multirow[b]{2}{*}{ Factors } & \multicolumn{5}{|c|}{ Descriptive statistics } & \multirow{2}{*}{$\begin{array}{l}\text { Mann-Kendall } \\
\text { trend test }\end{array}$} & \multicolumn{2}{|c|}{ Pettitt's test } & \multirow{2}{*}{$\begin{array}{l}\text { Sen's } \\
\text { slope }\end{array}$} \\
\hline & $\bar{N}$ & Mean & $\mathrm{SD}$ & $\mathrm{CV}$ & Slope & & $p$ & Mutation year & \\
\hline Temperature $\left({ }^{\circ} \mathrm{C}\right)$ & 36 & -8.79 & 0.84 & 0.10 & 0.03 & 1.87 & 0.02 & 1997 & 0.03 \\
\hline Precipitation (mm) & 36 & 336.23 & 48.45 & 0.14 & 1.64 & $1.98^{*}$ & 0.05 & 1994 & 1.85 \\
\hline Streamflow $\left(10^{8} \mathrm{~m}^{3}\right)$ & 36 & 36.14 & 6.68 & 0.18 & 0.25 & $2.71^{* *}$ & 0.001 & 2000 & 0.26 \\
\hline
\end{tabular}

Note: $*$ Indicates the significance of $a=0.05 . * *$ Indicates the significance of $a=0.01$.

Table 3. Seasonal Mann-Kendall test of the monthly temperature, precipitation and streamflow from 1980 to 2015.

\begin{tabular}{|c|c|c|c|c|}
\hline Factors & $N$ & $\begin{array}{c}\begin{array}{c}\text { Seasonal Mann- } \\
\text { Kendall test }\end{array} \\
Z\end{array}$ & $\begin{array}{c}\begin{array}{c}\text { Seasonal Mann- } \\
\text { Kendall test } \\
\text { with correlations }\end{array} \\
Z\end{array}$ & $\begin{array}{c}\text { Seasonal } \\
\text { Sen's } \\
\text { slope }\end{array}$ \\
\hline Temperature $\left({ }^{\circ} \mathrm{C}\right)$ & 432 & $2.6^{* *}$ & $2.2^{*}$ & 0.03 \\
\hline Precipitation (mm) & 432 & 1.0 & 0.9 & 0.01 \\
\hline Streamflow $\left(\mathrm{m}^{3} \mathrm{~s}^{-1}\right)$ & 432 & $3.9^{* * *}$ & 1.5 & 0.41 \\
\hline
\end{tabular}

Note: $*$ Indicates the significance of $a=0.05 . * *$ Indicates the significance of $a=0.01$.

$* * *$ Indicates the significance of $a=0.001$. 
streamflow are all increasing $(Z>0$; slope $>0)$. The increasing trends of temperature and streamflow are both significant $(a=0.01 ; a=0.001)$. The Kaidu River basin has become warmer and wetter in the recent $40 \mathrm{yr}$, which confirms Xu's et al (2008) research. The increasing streamflow indicates the positive trends in recycling ratio with global warming trends (Dirmeyer and Brubaker 2006).

The average and the slope of the downscaled grid annual temperature before and after the mutation year show the spatial and temporal variability of temperature (figure 5). The spatial distributions of temperature are consistent before and after the mutation year. The temperature in valleys is generally above $0^{\circ} \mathrm{C}$ while in mountainous areas it is usually below $0^{\circ} \mathrm{C}$. However, the trends of temperature are different before and after the mutation year. From 1980 to 1997, the temperature is continuously rising. The rising trend is high in some northeast mountains. From 1998 to 2015, the temperature decreases. During the 36 years from 1980 to 2015 , the temperature increases slowly.

The average and the slope of downscaled grid annual precipitation before and after the mutation year show the spatial and temporal variability of precipitation (figure 6). The precipitation decreases from the west and north to the middle and south in all the periods. The precipitation is the most abundant in the west and north mountains and the least in the southern valleys and mountains. However, the precipitation trends are different before and after the mutation year. From 1980 to 1994, the trend of precipitation rises from west to east. From 1995 to 2015, the precipitation in the whole basin reduces. From 1980 to 2015, the precipitation is increasing, and the trend in the eastern basin is higher than the west basin.

The EEMD method was used to decompose downscaled climate and streamflow series in the Kaidu River basin from 1980 to 2015. Figure 7 shows IMF components of temperature $(a)$, precipitation $(b)$ and streamflow $(c)$. For each time series, seven IMF components and one RES component (trend) were calculated. IMF components at different frequencies indicate the fluctuation characteristics at corresponding time scales, and the RES component shows the tendency of the original time series. The physical meaning of IMF components is the oscillation at different scales
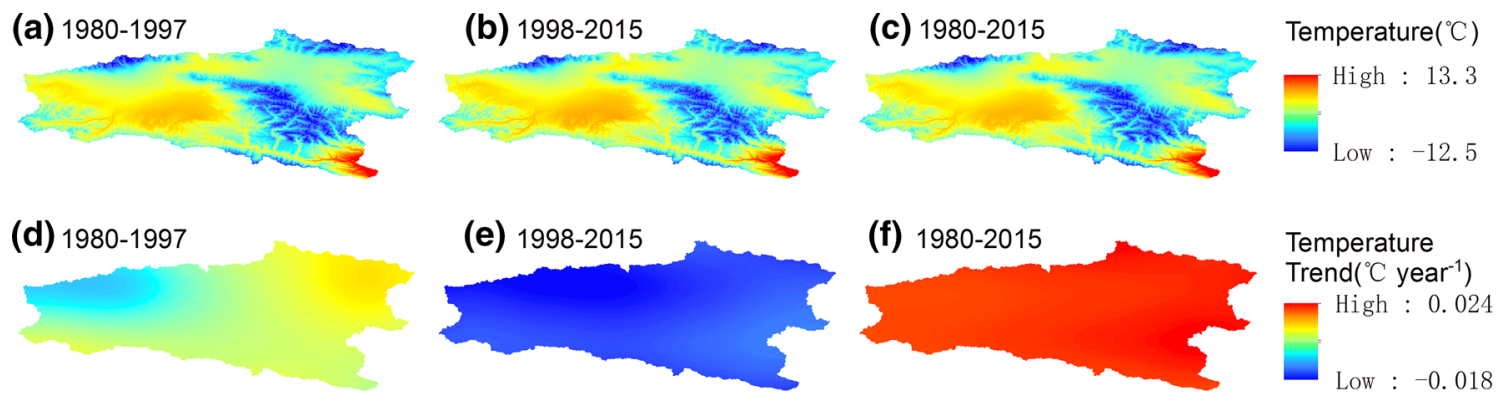

Figure 5. (a) Shows the average annual temperature from 1980 to 1997; (b) shows the average annual temperature from 1998 to 2015; (c) shows the average annual temperature from 1980 to 2015; (d) shows the slope of annual temperature from 1980 to 1997; (e) shows the slope of annual temperature from 1998 to 2015; and (f) shows the slope of annual temperature from 1980 to 2015 .

(a) $1980-1994$

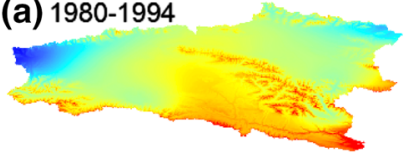

(d) $1980-1994$ (b) $1995-2015$

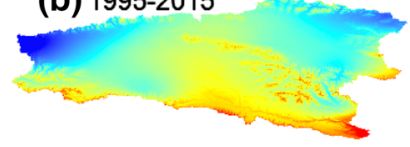

(e) $1995-2015$

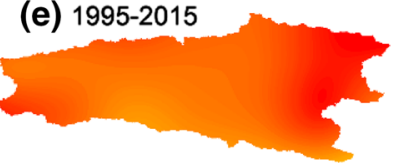

(c) $1980-2015$

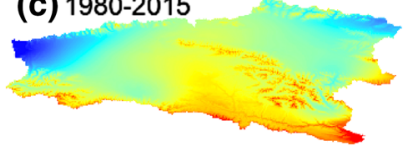

(f) $1980-2015$

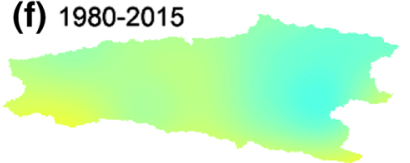

Precipitation(mm)

High : 522.3

Low : 0.0

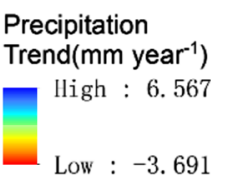

Figure 6. (a) Shows the average annual precipitation from 1980 to 1994; (b) shows the average annual precipitation from 1995 to 2015; (c) shows the average annual precipitation from 1980 to 2015; (d) shows the slope of annual precipitation from 1980 to 1994; (e) shows the slope of annual precipitation from 1995 to 2015; (f) shows the slope of annual precipitation from 1980 to 2015 . 
in the original time series. The significance test and confidence levels can indicate oscillation intensity.

It shows that the IMF1 and IMF2 of monthly temperature series, the IMF1, IMF2 and IMF3 of monthly precipitation series and all the IMF components of monthly streamflow series fell above 95\% confidence level (figure 8). The significance tests indicate that these IMF components contain more oscillation information and have more actual physical meaning.

Table 4 shows the variance contribution rate of IMF components on the original series. It can be found that the contribution of the 3-month cycle (IMF1) towards temperature, precipitation and streamflow variance is largest, reaching $67.63 \%$, $35.24 \%$, and $57.09 \%$, respectively. The variance contribution of RES component can be up to $31.32 \%, 49.57 \%$ and $29.13 \%$. So, the increasing trend of temperature and the first increasing and then decreasing trend of precipitation and streamflow are all significant.

Figure 9 shows the inter-seasonal, inter-annual, inter-decadal variations and the trend of the temperature, precipitation and streamflow series. IMF1 reconstructs the inter-seasonal sequence of temperature and streamflow. IMF1 and IMF2 reconstruct the inter-seasonal sequence of precipitation. Summation of IMF2, IMF3, IMF4 and IMF5 reconstructs the inter-annual set of temperature and streamflow. Summation of IMF3, IMF4 and IMF5 reconstructs the inter-annual set of precipitation. Summation of IMF6 and IMF7 reconstructs the inter-annual sequence of temperature, precipitation and streamflow. From table 4 and figure 9, it can be found that the reconstructed inter-seasonal variation and inter-annual variation are the significant fluctuations of the original monthly climate and streamflow series. Inter-decadal variability is a complicated and long-term process. It can be found (a)
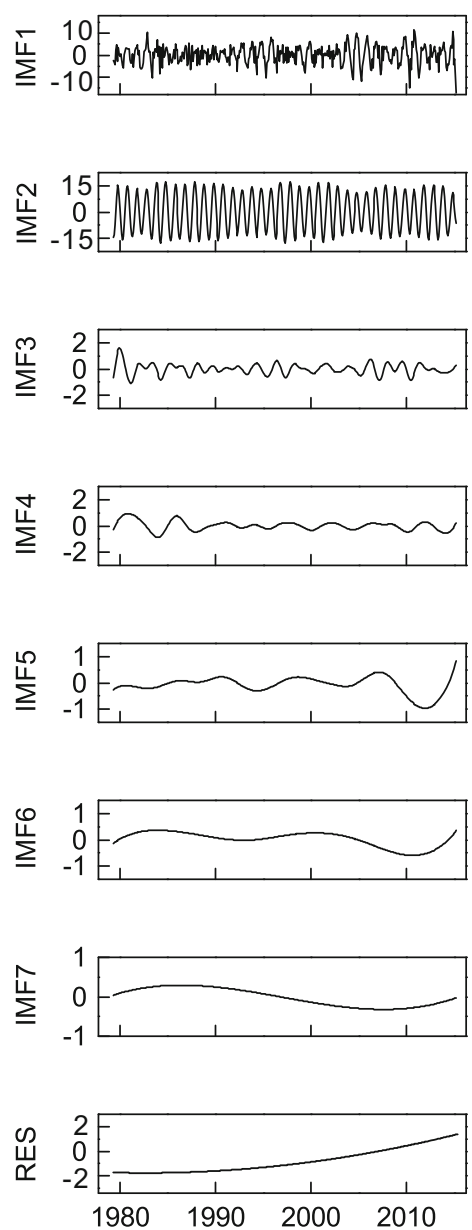

(b)
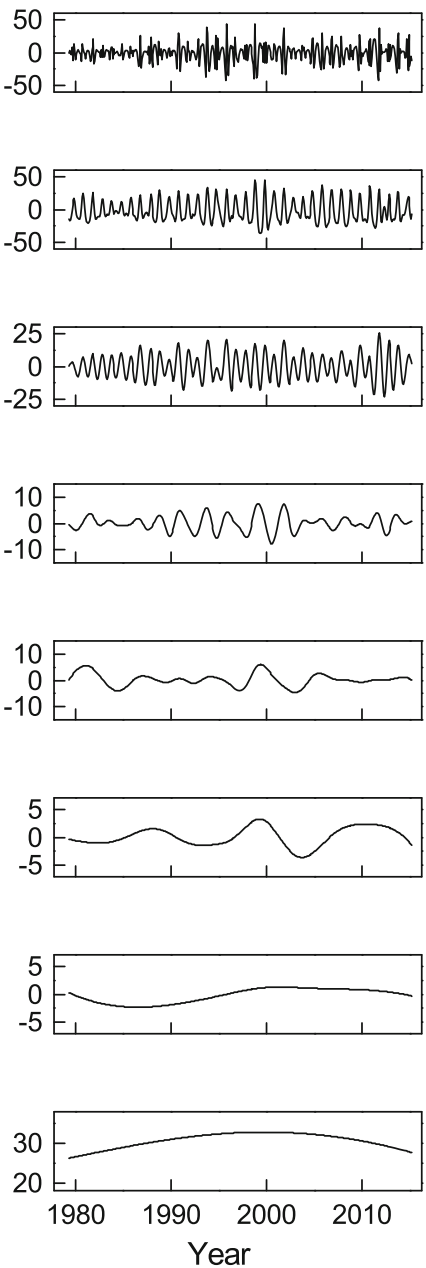

(c)
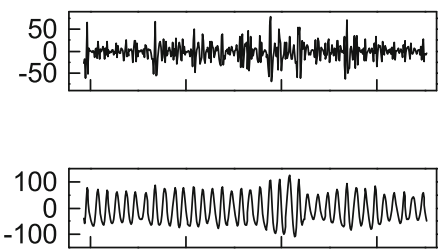

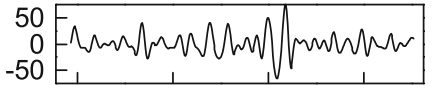
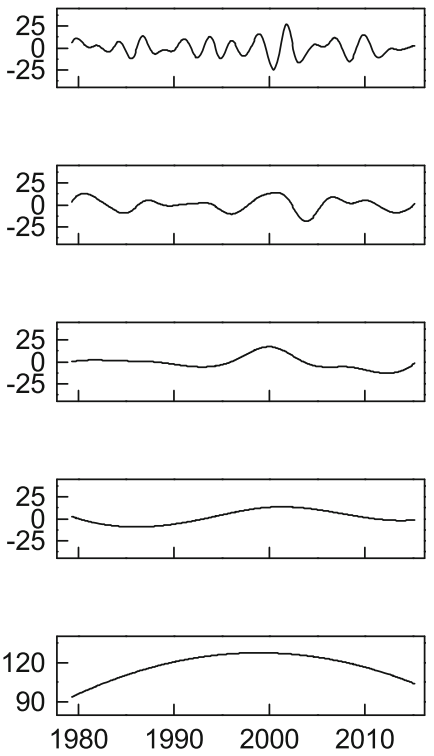

Figure 7. IMF components of temperature (a), precipitation (b) and streamflow (c) by the EEMD method. 

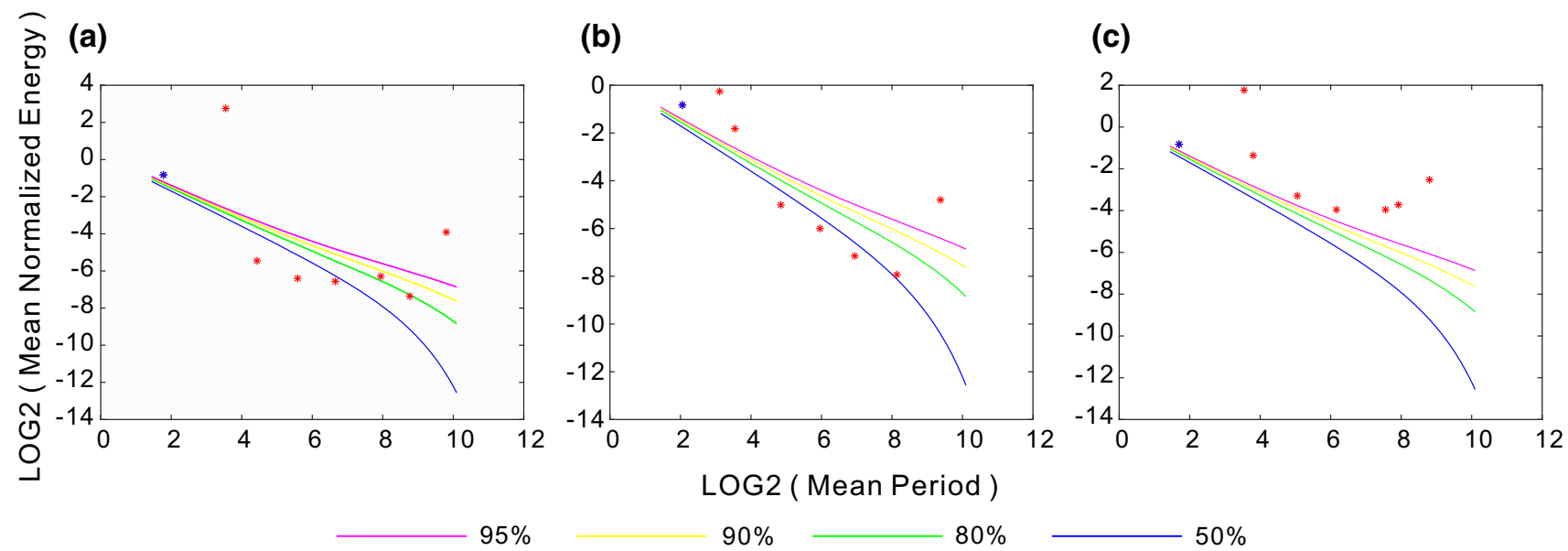

Figure 8. Significance test for the IMFs of temperature (a), precipitation (b), and streamflow (c) during the period of 1980-2015.

Table 4. Contribution rates of EEMD decomposition for temperature anomaly, precipitation anomaly and streamflow anomaly.

\begin{tabular}{lllllllll}
\hline IMF components & IMF1 & IMF2 & IMF3 & IMF4 & IMF5 & IMF6 & IMF7 & RES \\
\hline $\begin{array}{l}\text { Period (month) } \\
\text { Temperature }\end{array}$ & 3 & 12 & 22 & 48 & 100 & 246 & 435 & \\
Precipitation & 3 & 9 & 12 & 28 & 62 & 123 & 282 & 242 \\
Streamflow & 3 & 12 & 14 & 33 & 72 & 188 & & \\
Contribution (\%) & & & & & & & & \\
Temperature & 67.63 & 0.23 & 0.12 & 0.10 & 0.12 & 0.06 & 0.41 & 31.32 \\
Precipitation & 35.24 & 12.12 & 1.33 & 0.66 & 0.30 & 0.17 & 0.61 & 49.57 \\
Streamflow & 57.09 & 6.66 & 1.75 & 1.10 & 1.10 & 1.26 & 1.90 & 29.13 \\
\hline
\end{tabular}

that the streamflow is affected by both temperature and precipitation. The streamflow fluctuates from 1980 to 2015 . According to the last decadal fluctuation, the streamflow in the Kaidu River will present an apparent increasing trend over the next decade with the increasing temperature. By comparing the trend series, with the rising temperature, the streamflow presents a firstly increasing and then decreasing trend and is consistent with the precipitation trend. The increasing streamflow in the next decade may be due to an increase in temperature and snowmelt water. However, in the long term, rising temperatures may lead to reduced winter snowfall. If the precipitation reduces in the future, streamflow will decrease as the combined effects of temperature and precipitation.

\subsection{Impact of temperature and precipitation on streamflow}

With the downscaled monthly climate data, the BPANN simulates the monthly streamflow (figure 10). As a river supplied by precipitation and snow meltwater, the maximum of streamflow occurs in summer with large inter-annual change and the minimum of streamflow appears in winter with stable inter-annual change. The BPANN-simulated streamflow can show the nonlinear variation of monthly streamflow and need to be improved to simulate the maximum of streamflow. Table 5 shows the performance of BPANN. The slope is near 1 and shows that the simulated and observed streamflow is consistent. The NSE is close to 1 illustrating that the BPANN we contrasted can simulate the streamflow in the mountainous basins well. Compared to observed streamflow, the MAE and the RMSE are relatively small which indicate simulation results are of high precision. The impact of the temperature and precipitation on the streamflow is $44.21 \pm 2.08 \%$ and $55.79 \pm 2.08 \%$ in the Kaidu basin.

In summary, the BPANN model can well simulate the complex and nonlinear relationship between the monthly meteorological series and streamflow. The integrated approach with good 

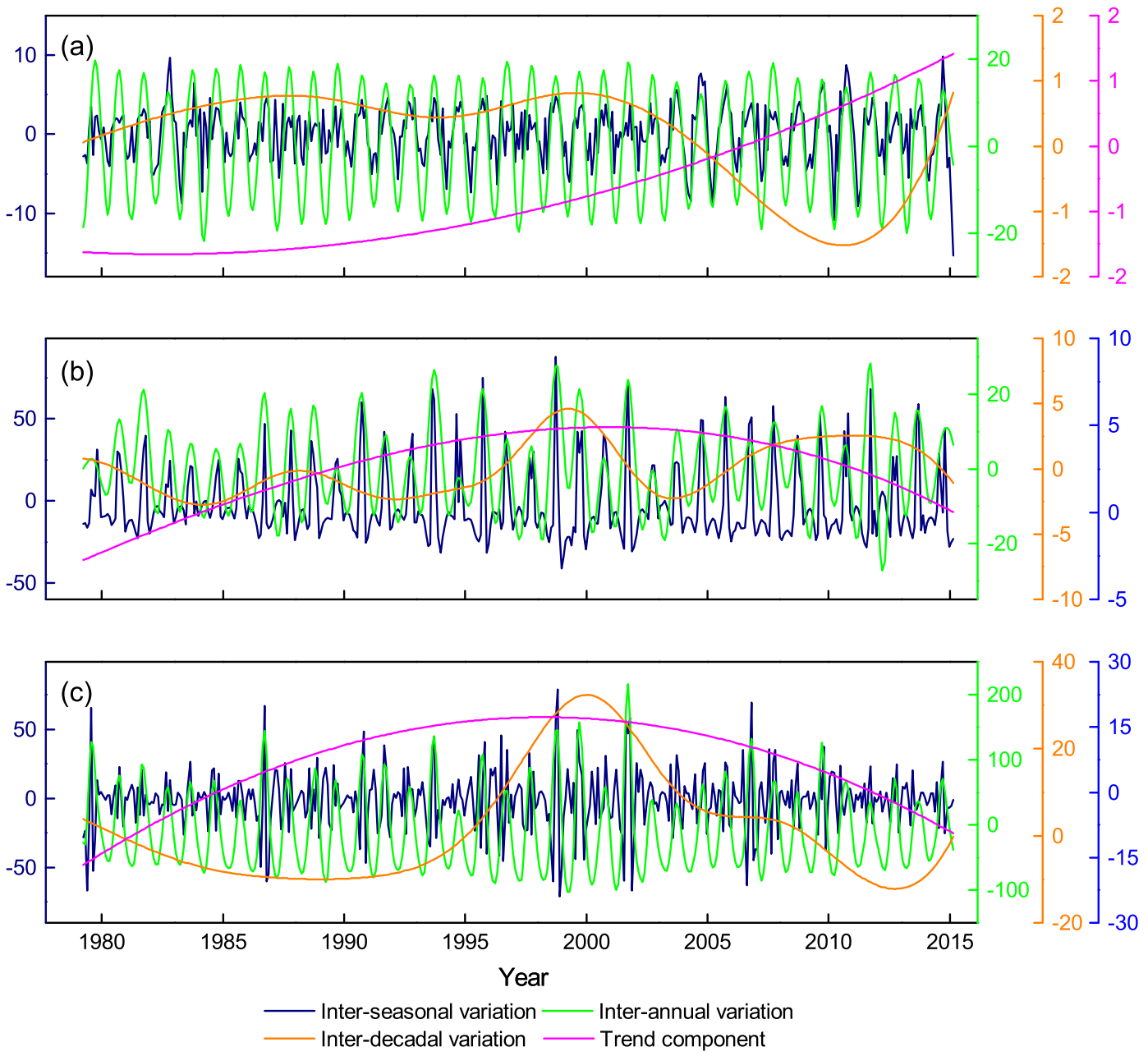

Figure 9. Inter-seasonal, inter-annual, inter-decadal variations and trend of temperature (a), precipitation (b), and streamflow $(\mathbf{c})$.

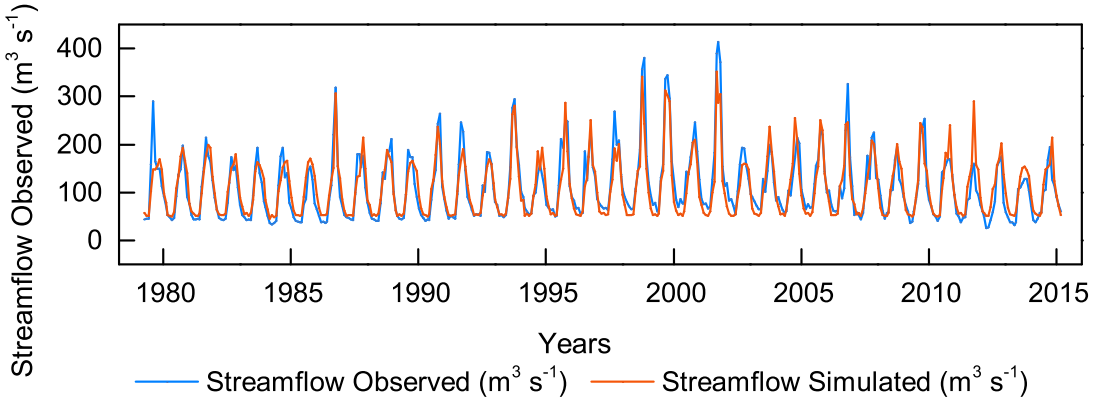

Figure 10. Monthly observed and BPANN-simulated streamflows during 1980-2015.

Table 5. Performance of BPANN and the contribution of climate change on streamflow.

\begin{tabular}{lllllllll}
\hline & \multicolumn{5}{c}{ Accuracy test } & & \multicolumn{2}{c}{ Contribution (\%) } \\
\cline { 2 - 5 } Rivers & $N$ & Slope & NSE & MAE & RMSE & & Temperature & Precipitation \\
\hline Kaidu River & 432 & 0.81 & 0.83 & 19.70 & 28.07 & & $44.21 \pm 2.08$ & $55.79 \pm 2.08$ \\
\hline
\end{tabular}


performance guarantees the realisation of the weight connection method to quantitatively assess the impact of climate change on streamflow.

\section{Conclusions}

To simulate the climate-driven streamflow and assess the impact of climate change to streamflow in data-scarce mountain basins of Northwest China, we developed an integrated approach by downscaling reanalysis data and multi-methods. It has been proved that the approach presents a good performance, which can be used to simulate the climate-driven streamflow and assess the impact of climate change to streamflow in datascarce mountain basins in Northwest China. Using the approach to investigate the Kaidu River basin in the Tianshan mountains of Northwest China, we obtained the following results: (i) the average annual temperature increased $5.2 \%$ by $0.3^{\circ} \mathrm{C}$ per decade and the precipitation increased $37.3 \%$ by $16.4 \mathrm{~mm}$ per decade during the period from 1980 to 2015 . (ii) With the warming and wetting climate, the streamflow increased $12.9 \%$ by $2.5 \times 10^{8} \mathrm{~m}^{3}$ per decade in the Kaidu River basin. (iii) The impact of the temperature and precipitation to streamflow is $44.21 \pm 2.08 \%$ and $55.79 \pm 2.08 \%$.

\section{Acknowledgements}

This work was supported by the National Natural Science Foundation of China (Grant Nos. 41871025 and 41630859); the Strategic Priority Research Program of the Chinese Academy of Sciences (Grant No. XDA19030204); and the Open Foundation of State Key Laboratory, Desert and Oasis Ecology, Xinjiang Institute of Ecology and Geography, Chinese Academy of Sciences (Grant No. G2014-02-07).

\section{References}

Arnold J G and Fohrer N 2005 SWAT2000 current capabilities and research opportunities in applied watershed modeling; Hydrol. Process. 19(3) 563-572.

Arnold J G, Srinivasan R, Muttiah R S and Williams J R 1998 Large-area hydrologic modeling and assessment: Part I. Model development; J. Am. Water Resour. Assoc. 34(1) 73-89.

Bai L, Xu J, Chen Z, Li W, Liu Z, Zhao B and Wang Z 2015 The regional features of temperature variation trends over Xinjiang in China by the ensemble empirical mode decomposition method; Int. J. Climatol. 35(11) 3229-3237.
Chen R, Kang E, Yang J and Wang S 2003 Monthly runoff model in mountainous region of Heihe Mainstream River; Arid Land Geogr. 26(1) 37-43.

Chen Y, Xu C, Chen Y, Liu Y and Li W 2013 Progress, challenges and prospects of Eco-hydrological studies in the Tarim river basin of Xinjiang, China; Environ. Manag. 51(1) 138-153.

Dirmeyer P and Brubaker K 2006 Evidence for trends in the Northern Hemisphere water cycle; Geophys. Res. Lett. 33(14) 1-4.

Emanuel K, Oouchi K, Satoh M, Tomita H and Yamada Y 2010 Comparison of explicitly simulated and downscaled tropical cyclone activity in a high-resolution global climate model; J. Adv. Model Earth Syst. 2(4) 289-298.

Feng H, Fang Y, Xiang X, Li J and Li G 2012 A datadriven noise reduction method and its application for the enhancement of stress wave signals; Sci. World J. 2012(1971) 353081.

Feng J, Wu Z and Liu G 2014 Fast multidimensional ensemble empirical mode decomposition using a data compression technique; J. Clim. 27(10) 3492-3504.

Fischer A 2015 How to determine the unique contributions of input-variables to the nonlinear regression function of a multilayer perceptron; Ecol. Model. 309-310 60-63.

Fu A, Chen Y, Li W, Li B, Yang Y and Zhang S 2013 Spatial and temporal patterns of climate variations in the Kaidu River Basin of Xinjiang, Northwest China; Quat. Int. 311(11) 117-122.

Georgakakos K P, Graham N E, Modrick T M, Murphy M J, Shamir E, Spencer C R and Sperfslage J A 2014 Evaluation of real-time hydrometeorological ensemble prediction on hydrologic scales in northern California; J. Hydrol. 519(Part D) 2978-3000.

Ghane M, Alvankar S, Eslamian S, Ostad-Ali-Askari K, Gandomkar A, Dehghan S, Singh V and Dalezios N 2017 A study on the effects of earth surface and metrological parameters on river discharge modeling using SWAT model, case study: Kasillian Basin, Mazandaran Province, Iran; Int. J. Constr. Res. Civil Eng. 3(4) 99-120.

Hipel K and Mcleod T 1994 Time series modelling of water resources and environmental systems; J. Hydrol. 167(14) 399-400.

Hirsch R, Slack J and Smith R 1982 Techniques of trend analysis for monthly water quality data; Water Resour. Res. 18(1) 107-121.

Huang N and Shen S 2005 Hilbert-Huang transform and its applications; World Scientific Publishing Co. Pte. Ltd., Hackensack, NJ.

Huang N, Shen Z, Long S, Wu M, Shih H, Zheng Q, Yen N, Tung C and Liu H 1998 The empirical mode decomposition and the Hilbert spectrum for nonlinear and non-stationary time series analysis; Proc. Math. Phys. Eng. Sci. 454(1971) 903-995.

Huth R, Mikšovský J, Štěpánek P, Belda M, Farda A, Chládová Z and Pišoft P 2015 Comparative validation of statistical and dynamical downscaling models on a dense grid in central Europe: Temperature; Theor. Appl. Climatol. 120(3-4) 533-553.

Ji F, Wu Z, Huang J and Chassignet E 2014 Evolution of land surface air temperature trend; Nat. Clim. Change 4(6) $462-466$. 
Kendall M 1948 Rank correlation methods; Oxford University Press, England.

Khaliq M, Ouarda T, Gachon P, Sushama L and St-Hilaire A 2009 Identification of hydrological trends in the presence of serial and cross correlations: A review of selected methods and their application to annual flow regimes of Canadian rivers; J. Hydrol. 368(1) 117-130.

Koster R, Betts A, Dirmeyer P, Bierkens M, Bennett K, Déry S, Evans J, Fu R, Hernandez F, Leung L, Liang X, Masood M, Savenije H, Wang G and Yuan X 2017 Hydroclimatic variability and predictability: A survey of recent research; Hydrol. Earth Syst. Sci. 21(7) 3777-3798.

Lévesque É and Anctil F 2008 Evaluation of streamflow simulation by SWAT model for two small watersheds under snowmelt and rainfall; Hydrolog. Sci. J. 53(5) 961-976.

Li B, Chen Y, Chen Z and Li W 2012 Trends in runoff versus climate change in typical rivers in the arid region of northwest China; Quat. Int. 282 87-95.

Loukas A and Vasiliades L 2014 Streamflow simulation methods for ungauged and poorly gauged watersheds; Nat. Hazard Earth Syst. 14(7) 1641-1661.

Mann H B 1945 Nonparametric tests against trend; Econometrica: J. Econ. Soc. 1945 245-259.

$\mathrm{Mu} \mathrm{X,} \mathrm{Li} \mathrm{J,} \mathrm{Wang} \mathrm{F} \mathrm{and} \mathrm{Wang} \mathrm{W} 2004$ Rainfall-runoff statistical hydrological model based on soil and water conservation practices; J. Hydraul. Eng. 35(5) 122-128.

Olden J and Jackson D 2002 Illuminating the 'black box': A randomization approach for understanding variable contributions in artificial neural networks; Ecol. Model. 154(1-2) 135-150.

Olden J D, Joy M K and Death R G 2004 An accurate comparison of methods for quantifying variable importance in artificial neural networks using simulated data; Ecol. Model. 178 389-397.

Pereira D, Martinez M, Pruski F and Silva D 2016 Hydrological simulation in a basin of typical tropical climate and soil using the SWAT model. Part I: Calibration and validation tests; J. Hydrol. Reg. Stud. 7(C) 14-37.

Pettitt A 1979 A non-parametric approach to the changepoint problem; J. R. Stat. Soc. 28(2) 126-135.

Qian C and Zhou T 2014 Multidecadal variability of North China Aridity and its relationship to PDO during 19002010; J. Clim. 27(3) 1210-1222.

Qian C, Fu C and Wu Z 2011 Changes in the amplitude of the temperature annual cycle in China and their implication for climate change research; J. Clim. 24(20) 5292 5302 .

Reuter H, Nelson A and Jarvis A 2007 An evaluation of voidfilling interpolation methods for SRTM data; Int. J. Geo. Inf. Sci. 21(9) 983-1008.

Shope C, Maharjan G, Tenhunen J, Seo B, Kim K, Riley J, Arnhold S, Koellner T, Ok Y, Peiffer S, Kim B, Park $\mathrm{J}$ and Huwe B 2014 Using the SWAT model to improve process descriptions and define hydrologic partitioning in South Korea; Hydrol. Earth Syst. Sci. 18(2) 539557 .
Sivakumar B 2010 Nonlinear determinism in river flow: Prediction as a possible indicator; Earth Surf. Process. Landf. 32(7) 969-979.

Sonali P and Kumar D 2013 Review of trend detection methods and their application to detect temperature changes in India; J. Hydrol. 476(1) 212-227.

Strzepek K, Schlosser A, Gueneau A, Gao X, Blanc E, Fant C, Rasheed B and Jacoby H 2013 Modeling water resource systems within the framework of the MIT integrated global system model: IGSM-WRS; J. Adv. Model Earth Syst. 5(3) 638-653.

Wang H, Chen Y and Chen Z 2013 Spatial distribution and temporal trends of mean precipitation and extremes in the arid region, northwest of China, during 1960-2010; Hydrol. Process. 27(12) 1807-1818.

Wang C, Xu J, Chen Y, Bai L and Chen Z 2018 A hybrid model to assess the impact of climate variability on streamflow for an ungauged mountainous basin; Clim. Dyn. 50(7-8) 2829-2844.

Wu Z and Huang N 2004 A study of the characteristics of white noise using the empirical mode decomposition method; Proc. Math. Phys. Eng. Sci. 460(2046) 15971611.

Wu Z and Huang N 2009 Ensemble empirical mode decomposition: A noise-assisted data analysis method; Adv. Adap. Data Anal. 1(01) 1-41.

Xu J, Chen Y, Ji M and Lu F 2008 Climate change and its effects on runoff of Kaidu river, Xinjiang, China: A multiple time-scale analysis; Chinese Geogr. Sci. 18(4) 331-339.

Xu J, Chen Y, Lu F, Li W, Zhang L and Hong Y 2011 The nonlinear trend of runoff and its response to climate change in the Aksu River, western China; Int. J. Climatol. 31(5) 687-695.

Xu J, Chen Y, Li W, Peng P, Yang Y, Song C, Wei C and Hong Y 2013 Combining BPANN and wavelet analysis to simulate hydro-climatic processes - A case study of the Kaidu River, North-west China; Front. Earth Sci. $\mathbf{7 ( 2 )}$ $227-237$.

Xu J, Chen Y, Li W, Nie Q, Song C and Wei C 2014 Integrating wavelet analysis and BPANN to simulate the annual runoff with regional climate change: A case study of Yarkand River, Northwest China; Water Resour. Manag. 28(9) 2523-2537.

Xu J, Chen Y, Bai L and Xu Y 2016 A hybrid model to simulate the annual runoff of the Kaidu River in northwest China; Hydrol. Earth Syst. Sci. 20(4) 1447-1457.

Yang D and Musiake K 2003 A continental scale hydrological model using the distributed approach and its application to Asia; Hydrol. Process. 17(14) 2855-2869.

Yang D, Gao B, Jiao Y, Lei H, Zhang Y, Yang H and Cong Z 2015 A distributed scheme developed for eco-hydrological modeling in the upper Heihe River; Sci. China Ser. D 58(01) 36-45.

Yao J, Zhao Y, Chen Y, Yu X and Zhang B 2018 Multi-scale assessments of droughts: A case study in Xinjiang, China; Sci. Total Environ. 630 444-452. 